Chika Anele Ndubuisi,

Wilfred C. Mezue, Samuel C. Ohaegbulam

Department of Neurosurgery, Memfys Hospital for Neurosurgery, Enugu, Nigeria

\section{Corresponding Author:}

Chika Anele Ndubuisi

Department of Neurosurgery,

Memfys Hospital for Neurosurgery,

$\mathrm{Km}$ 2, Enugu-Onitsha

Expressway, Enugu2292, Nigeria

Tel: +2348034360540

Fax: +2348034360540

E-mail: chikandu@yahoo.com

Received: April 25, 2017

Revised: June 20, 2017

Accepted: June 23, 2017

\title{
Space Available for the Cervical Spinal Cord of Asymptomatic Adult Nigerians
}

Objective: The space available for the spinal cord (SAC) is a measure of spinal cord functional reserve and may vary in different societies. The objective of this study is to measure normal SAC at each subaxial cervical disc level of asymptomatic adult Nigerians and to compare obtained values with published studies worldwide.

Methods: This is a prospective, cross-sectional study using magnetic resonance imaging facility at Memfys Hospital Enugu, from 2012 to 2013. Disc level measurement of midsagittal spinal canal and cord of randomly selected 102 consenting asymptomatic adults, 21 to 50 years. Literature search of related studies worldwide was used to compare with the current study. Analysis was done using inferential and descriptive statistics.

Results: Average SAC values were 4.9 $\pm 1.4 \mathrm{~mm}(\mathrm{C} 3 / 4), 4.5 \pm 1.2 \mathrm{~mm}(\mathrm{C} 4 / 5), 4.6 \pm 1.4 \mathrm{~mm}(\mathrm{C} 5 / 6)$, and $4.9 \pm 1.2 \mathrm{~mm}(\mathrm{C} 6 / 7)$. In 21-30 years group, SAC was $5.4 \pm 0.6 \mathrm{~mm}(\mathrm{C} 3 / 4), 4.9 \pm 0.6 \mathrm{~mm}(\mathrm{C} 4 / 5)$, $4.9 \pm 0.6 \mathrm{~mm}(\mathrm{C} 5 / 6)$, and $5.1 \pm 0.5 \mathrm{~mm}(\mathrm{C} 6 / 7)$. In $31-40$ years group, SAC was $5.4 \pm 0.5 \mathrm{~mm}(\mathrm{C} 3 / 4)$, $4.6 \pm 0.5 \mathrm{~mm}(\mathrm{C} 4 / 5), 4.9 \pm 0.6 \mathrm{~mm}(\mathrm{C} 5 / 6)$, and 5.3 $\pm 0.6 \mathrm{~mm}(\mathrm{C} 6 / 7)$; but among 41-50 years group, SAC was $3.8 \pm 0.6 \mathrm{~mm}(\mathrm{C} 3 / 4), 3.9 \pm 0.6 \mathrm{~mm}(\mathrm{C} 4 / 5), 3.6 \pm 0.6 \mathrm{~mm}(\mathrm{C} 5 / 6)$, and $4.3 \pm 0.6 \mathrm{~mm}(\mathrm{C} 6 / 7)$. In females SAC was $4.9 \pm 1.3 \mathrm{~mm}(\mathrm{C} 3 / 4), 4.5 \pm 1.2 \mathrm{~mm}(\mathrm{C} 4 / 5), 4.6 \pm 1.2 \mathrm{~mm}(\mathrm{C} 5 / 6)$, and $4.8 \pm 1.1 \mathrm{~mm}$ (C6/7). In males, SAC was 4.9 $\pm 1.4 \mathrm{~mm}(\mathrm{C} 3 / 4), 4.6 \pm 1.2 \mathrm{~mm}(\mathrm{C} 4 / 5), 4.5 \pm 1.5 \mathrm{~mm}(\mathrm{C} 5 / 6)$, and $5.1 \pm$ $1.3 \mathrm{~mm}(\mathrm{C} 6 / 7)$. From analysis of variance, impact of age on SAC was $0.118(p=0.001)$ while gender had $0.078(p=0.223)$. SAC at each level has positive correlation of 0.6 to 0.7 with adjacent levels $(p<0.0001)$. Comparing this result with studies worldwide, our population has lower SAC values than others.

Conclusion: C4/5 and C5/6 are narrowest subaxial cervical spine levels and probably explain preponderance of $\mathrm{C} 4 / 5$ and $\mathrm{C} 5 / 6$ cord injury. There may be higher incidence of congenital canal stenosis predisposing to worse outcome following cervical spine injury or degenerative diseases in this study population. This is different from European series but similar to Japanese.

Key Words: SAC, Asymptomatic, Nigeria

\section{INTRODUCTION}

The space available for the spinal cord (SAC) is the cerebrospinal fluid space around the spinal cord. It is a direct indicator for stenosis as well as a useful tool for prediction of risk of myelopathy and prognosis following spinal cord injury in an individual ${ }^{4,9}$. SAC has been argued to be a reliable canal stenosis indicator when measured with magnetic resonance imaging (MRI). Measurement with plain radiographs and even with plain computed tomography are not as reliable ${ }^{1,5,14)}$.

Many factors, including race, sex, and age have been demonstrated to influence the $\mathrm{SAC}^{4,6,10,11)}$. This implies that it may be wrong to extrapolate measurements derived from one study population to all populations. There is growing local burden of cervical spinal cord injury and early onset degenerative cervical myelopathy observed in the indigenous population in Nigeria. While this may partly be due to the increasing life expectancy, it is to some extent related to increasing availability of spine services in the country. There is therefore need to derive this cervical spine stenosis index for the Nigerian population.

This study analyzed the normal dimensions of the MRI derived SAC in the subaxial cervical spine of asymptomatic young adults in Enugu, Nigeria and compared the result with the literature to identify if any geographical difference exists.

\section{MATERIALS AND METHODS}

\section{Patients}

This is an MRI derived prospective, cross- 
sectional study using asymptomatic adult Nigerians between 21 years and 50 years old that reside in Enugu who met the inclusion criteria. The MRI facility at Memfys Hospital for Neurosurgery Enugu was used. Measurements were obtained at the disc levels. The study excluded individuals that participate in any form of contact sports activities, non-Nigerians, individuals with any symptom referable to the cervical spine or spinal cord, people with congenital deformities that may suggest predisposition to congenital canal stenosis, previous cervical spine surgeries, MRI scan finding of cervical spine disease or people with contraindications to the use of MRI. A total sample size of 102 young adults was selected using multistaged sampling from among students of the University of Nigeria and individuals that presented for MRI investigation for non-spine related indications. All patients signed informed consent before participating in the study. T1-weighted MRI scans were obtained and used in this study. T2 images were however obtained to rule out any subtle cervical spine pathology. Individuals that consented for the study had MRI of the cervical spine with BASDA 0.35T MRI machine (Schenzen BASDA Medical Apparatus Co., LTD., Shenzhen, China). Midsagittal disc-level spinal canal dimension $(\mathrm{Y})$ was taken as well as the corresponding level spinal cord dimension (X). SAC was calculated as $\mathrm{Y}-\mathrm{X}$ (Fig. 1).

\section{Statistical Analysis}

Data was analyzed using both descriptive and inferential statistics aided by the SPSS ver. 17.0 (SPSS Inc., Chicago, IL, USA). To assess the contributory effect of sex, age and subaxial spine

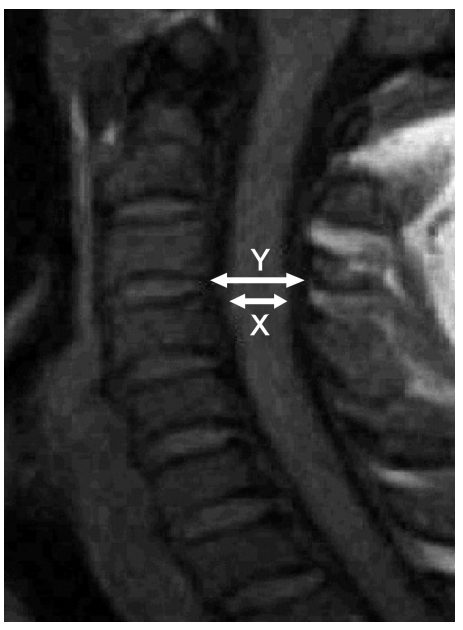

Fig. 1. T1-weighted magnetic resonance imaging of the midsagittal cervical spine with illustration of measurements obtained.

Table 1. Values of SAC at each subaxial cervical spine level

\begin{tabular}{cc}
\hline \hline Spine level & Mean \pm SD $(\mathrm{mm})$ \\
\hline SAC3 & $4.92 \pm 1.36$ \\
SAC4 & $4.52 \pm 1.24$ \\
SAC5 & $4.56 \pm 1.37$ \\
SAC6 & $4.97 \pm 1.22$ \\
SAC7 & $5.61 \pm 1.45$ \\
\hline
\end{tabular}

SAC, space available for the spinal cord; SD, standard deviation. levels on the value of SAC, a multivariate and univariate analysis of variance tests were conducted. This study was approved by the research ethical board of Memfys Hospital (MH/ADMIN/ C.112). All the subjects signed informed consent.

\section{RESULTS}

Average values of SAC were $4.9 \pm 1.4 \mathrm{~mm}(\mathrm{C} 3 / 4), 4.5 \pm 1.2 \mathrm{~mm}$ (C4/5), 4.6 $\pm 1.4 \mathrm{~mm}(\mathrm{C} 5 / 6), 4.9 \pm 1.2 \mathrm{~mm}(\mathrm{C} 6 / 7)$, and 5.6 \pm 1.5 $\mathrm{mm}$ at $\mathrm{C} 7 / \mathrm{T} 1$ (Table 1$)$. In 21-30 years group, SAC was 5.4 \pm 0.6

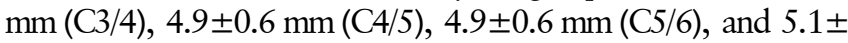
$0.5 \mathrm{~mm}(\mathrm{C6} / 7)$ (Table 2). In the $31-40$ years age group, SAC was $5.44 \pm 0.5 \mathrm{~mm}(\mathrm{C} 3 / 4), 4.6 \pm 0.5 \mathrm{~mm}(\mathrm{C} 4 / 5), 4.9 \pm 0.6 \mathrm{~mm}(\mathrm{C} 5 / 6)$, $5.3 \pm 0.5 \mathrm{~mm}(\mathrm{C} 6 / 7)$; but among $41-50$ years group, SAC was $3.8 \pm 0.6 \mathrm{~mm}(\mathrm{C} 3 / 4), 3.9 \pm 0.6 \mathrm{~mm}(\mathrm{C} 4 / 5), 3.6 \pm 0.6 \mathrm{~mm}(\mathrm{C} 5 / 6)$, and $4.3 \pm 0.6 \mathrm{~mm}(\mathrm{C6} / 7)$. There was statistically significant effect of age on the SAC $(p=0.0001)$ (Table 2). From analysis of variance (ANOVA) test, the impact of age on SAC was $0.118(\mathrm{p}=$ 0.001) (Table 3). Follow-up ANOVA indicates that the effect of age on SAC across the subaxial cervical spine levels varied from 0.316 at $\mathrm{C} 3 / 4(\mathrm{p}=0.0001) ; 0.247$ at $\mathrm{C} 7 / \mathrm{T} 1(\mathrm{p}=0.0001) ; 0.228$ at $\mathrm{C} 5 / 6(\mathrm{p}=0.0001) ; 0.213$ at $\mathrm{C} 6 / 7(\mathrm{p}=0.001) ; 0.145$ at $\mathrm{C} 4 / 5(\mathrm{p}=$ 0.015 ) (Table 4).

At C3/4 level, SAC in females was $4.9 \pm 1.3 \mathrm{~mm}$ and $4.9 \pm 1.4$ $\mathrm{mm}$ in males; at $\mathrm{C} 4 / 5$ it was $4.5 \pm 1.2 \mathrm{~mm}$ in females but $4.6 \pm 1.2$

Table 2. Normal age adjusted range of SAC values at each subaxial spine level

\begin{tabular}{|c|c|c|}
\hline Spine level \& age (yr) & Mean \pm SD $(\mathrm{mm})$ & SE \\
\hline \multicolumn{3}{|l|}{ SAC3 } \\
\hline $20-30$ & $5.41 \pm 0.56$ & 0.282 \\
\hline $31-40$ & $5.35 \pm 0.54$ & 0.274 \\
\hline $41-50$ & $3.78 \pm 0.60$ & 0.301 \\
\hline \multicolumn{3}{|l|}{ SAC4 } \\
\hline $20-30$ & $4.92 \pm 0.57$ & 0.286 \\
\hline $31-40$ & $4.64 \pm 0.55$ & 0.278 \\
\hline $41-50$ & $3.86 \pm 0.61$ & 0.306 \\
\hline \multicolumn{3}{|l|}{ SAC5 } \\
\hline $20-30$ & $4.91 \pm 0.60$ & 0.299 \\
\hline $31-40$ & $4.91 \pm 0.58$ & 0.291 \\
\hline $41-50$ & $3.64 \pm 0.64$ & 0.321 \\
\hline \multicolumn{3}{|l|}{ SAC6 } \\
\hline $20-30$ & $5.14 \pm 0.54$ & 0.271 \\
\hline $31-40$ & $5.30 \pm 0.52$ & 0.264 \\
\hline $41-50$ & $4.28 \pm 0.58$ & 0.291 \\
\hline \multicolumn{3}{|l|}{ SAC7 } \\
\hline $20-30$ & $5.90 \pm 0.63$ & 0.320 \\
\hline $31-40$ & $5.99 \pm 0.62$ & 0.311 \\
\hline $41-50$ & $4.69 \pm 0.68$ & 0.342 \\
\hline
\end{tabular}

SAC, space available for the spinal cord; SD, standard deviation; SE, standard error. $\mathrm{p}=0.0001, \mathrm{~T}=0.708$. 
Table 3. Multivariate analysis of effect of age and sex on the SAC

\begin{tabular}{|c|c|c|c|c|c|}
\hline Effect & Statistic & Value & F-value & p-value & $\begin{array}{c}\text { Partial eta squared } \\
\text { (effect size) }\end{array}$ \\
\hline Sex & Wilks' Lambda & 0.922 & 10.428 & 0.223 & 0.078 \\
\hline Age & Wilks' Lambda & 0.535 & 20.302 & 0.001 & 0.118 \\
\hline Sex $\times$ age & Wilks' Lambda & 0.738 & 10.068 & 0.379 & 0.059 \\
\hline
\end{tabular}

SAC, space available for the spinal cord.

Table 4. Univariate analysis of variance of effect of age on all the subaxial cervical spine levels

\begin{tabular}{lccc}
\hline \hline Age \& level & F-value & p-value & $\begin{array}{c}\text { Partial eta squared } \\
\text { (effect size) }\end{array}$ \\
\hline Age & & & \\
SAC3 & 8.134 & 0.000 & 0.316 \\
SAC4 & 2.993 & 0.015 & 0.145 \\
SAC5 & 5.198 & 0.000 & 0.228 \\
SAC6 & 4.754 & 0.001 & 0.213 \\
SAC7 & 5.778 & 0.000 & 0.247 \\
\hline
\end{tabular}

SAC, space available for the spinal cord.

Table 5. Effect of sex on the normal values of SAC at each subaxial spine level

\begin{tabular}{lcccc}
\hline \hline $\begin{array}{c}\text { Spine level } \\
\text { \& sex }\end{array}$ & $\begin{array}{c}\text { Mean } \pm \text { SD } \\
(\mathrm{mm})\end{array}$ & SE & $\begin{array}{c}\text { Mean difference } \\
(\mathrm{mm})\end{array}$ & p-value \\
\hline SAC3 & & & & \\
$\quad$ Female & $4.945 \pm 0.39$ & 0.195 & 0.045 & 0.870 \\
$\quad$ Male & $4.900 \pm 0.38$ & 0.191 & & \\
SAC4 & & & & \\
$\quad$ Female & $4.486 \pm 0.35$ & 0.178 & -0.730 & 0.770 \\
$\quad$ Male & $4.559 \pm 0.35$ & 0.175 & & \\
SAC5 & & & & \\
Female & $4.596 \pm 0.39$ & 0.197 & 0.076 & 0.782 \\
Male & $4.520 \pm 0.39$ & 0.193 & & \\
SAC6 & & & & \\
Female & $4.798 \pm 0.34$ & 0.173 & -0.337 & 0.168 \\
$\quad$ Male & $5.135 \pm 0.34$ & 0.170 & & \\
SAC7 & & & & \\
Female & $5.488 \pm 0.41$ & 0.208 & -0.232 & 0.427 \\
Male & $5.720 \pm 0.41$ & 0.204 & & \\
\hline
\end{tabular}

SAC, space available for the spinal cord; SD, standard deviation; SE, standard error.

$\mathrm{p}=0.241$. $\mathrm{T}=0.073$.

$\mathrm{mm}$ in males; at $\mathrm{C} 5 / 6 \mathrm{SAC}$ measured $4.6 \pm 1.2 \mathrm{~mm}$ in females and $4.5 \pm 1.5 \mathrm{~mm}$ in males while at $\mathrm{C} 6 / 7 \mathrm{SAC}$ measured $4.8 \pm 1.1$ $\mathrm{mm}$ in females but $5.1 \pm 1.3 \mathrm{~mm}$ in males. At C7/T1, SAC value was $5.5 \pm 1.4 \mathrm{~mm}$ in the females and $5.7 \pm 1.5 \mathrm{~mm}$ in the males (Table 5). There was no statistically significant difference in the values of SAC between the sex groups across different disc levels $(p=0.241)$. The mean difference between females and males at
Table 6. Correlation between SAC at adjacent segments

\begin{tabular}{lllll}
\hline \hline Spine level & SAC3 & SAC4 & SAC5 & SAC6 \\
\hline SAC4 & & & & \\
Pearson correlation & $0.686^{* * *}$ & - & - & - \\
Sig. (2-tailed) & 0.000 & - & - & - \\
SAC5 & & & & \\
Pearson correlation & $0.650^{* * *}$ & $0.722^{* * *}$ & - & - \\
Sig. (2-tailed) & 0.000 & 0.000 & - & - \\
SAC6 & & & & \\
Pearson correlation & $0.635^{* * *} 0.684 * * *$ & $0.750^{* * *}$ & - \\
Sig. (2-tailed) & 0.000 & 0.000 & 0.000 & - \\
SAC7 & & & & \\
Pearson correlation & $0.599 * * *$ & $0.612^{* * *}$ & $0.645^{* * *}$ & $0.676^{* * *}$ \\
Sig. (2-tailed) & 0.000 & 0.000 & 0.000 & 0.000 \\
\hline SAC, space available for the spinal cord. & & \\
$* * *$ p=0.001. & & & &
\end{tabular}

C3/4 was $0.045 \mathrm{~mm}(\mathrm{p}=0.870),-0.73 \mathrm{~mm}$ at $\mathrm{C} 4 / 5(\mathrm{p}=0.770)$, $0.076 \mathrm{~mm}$ at $\mathrm{C} 5 / 6(\mathrm{p}=0.782),-0.337 \mathrm{~mm}$ at $\mathrm{C} 6 / 7$ level $(\mathrm{p}=0.168)$ (Table 5). From ANOVA test, the effect of sex on SAC was $0.078(\mathrm{p}=0.223)$ (Table 3).

The correlation between the SAC at C3/4 with SAC at $\mathrm{C} 4 / 5$ was $0.686(p=0.001), 0.650$ at $\mathrm{C} 5 / 6(\mathrm{p}=0.001), 0.635$ at $\mathrm{C} 6 / 7$ $(\mathrm{p}=0.001)$, and 0.599 at $\mathrm{C} 7 / \mathrm{T} 1(\mathrm{p}=0.001)$. The correlation between $\mathrm{SAC}$ at $\mathrm{C} 4 / 5$ and $\mathrm{C} 5 / 6$ was $0.722(\mathrm{p}=0.001), 0.684$ with $\mathrm{C} 6 / 7(\mathrm{p}=0.001)$, and 0.612 with $\mathrm{C} 7 / \mathrm{T} 1(\mathrm{p}=0.001)$. The correlation between $\mathrm{SAC}$ at $\mathrm{C} 5 / 6$ and $\mathrm{C} 6 / 7$ was $0.750(\mathrm{p}=0.001)$ and 0.645 with $\mathrm{C} 7 / \mathrm{T} 1(\mathrm{p}=0.001)$. SAC at $\mathrm{C} 6 / 7$ has a correlation value of 0.676 with $\mathrm{C} 7 / \mathrm{T} 1(\mathrm{p}=0.001)$ (Table 6).

\section{DISCUSSION}

The finding from this study revealed that the $\mathrm{C} 4 / 5$ and $\mathrm{C} 5 / 6$ levels are the narrowest segments in the subaxial cervical spine in both sexes and across different age groups amongst adult $\mathrm{Ni}$ gerians. Since the spinal cord attains the maximal cervical spine dimension at the same levels due to brachial plexus enlargement further compromising the SAC, this anatomical narrowing may contribute to the preponderance of cervical cord injury at these levels.

Relatively, the SAC values obtained at each subaxial cervical spine level in this study environment were much smaller when compared to the findings from America and Eastern Europe ${ }^{7,914)}$. It is of interest however that the findings in our study were more similar to the findings among the Japanese population ${ }^{3)}$ (Table 7). A similar pattern of racial difference between Caucasians and Blacks was also observed in separate studies carried out in the United States and South Africa ${ }^{11,12)}$. Both genetic and environmental factors may explain the racial differences observed between this study and other parts of the world.

These findings have some significance. The relatively low SAC from this study population when compared to other studies also suggests that there may be significant racial disparity in the expec- 
Table 7. Mean SAC at different subaxial cervical spine levels from different studies

\begin{tabular}{|c|c|c|c|c|c|c|c|}
\hline Authors (country) & Age (yr) & Sample & C3 & $\mathrm{C} 4$ & $\mathrm{C5}$ & C6 & $\mathrm{C} 7$ \\
\hline Matveeva et al. 2012 (Croatia) $)^{7}$ & $26-64$ & 30 & 7.7 & $6.9^{*}$ & 7.0 & 7.7 & 8.7 \\
\hline Prasad et al. $2003(\mathrm{UK})^{8)}$ & $20-40$ & 87 & 43 & $4.0^{*}$ & 4.5 & 5.4 & - \\
\hline Tierney et al. 2002 (USA) ${ }^{14)}$ & $24 \pm 2.5$ & 14 & 5.6 & $5.3 *$ & $5.3 *$ & 5.7 & 7.1 \\
\hline Presciutti et al. 2009 (USA) ${ }^{9)}$ & $20-30$ & 119 & 6.6 & $6.5^{*}$ & 6.7 & 6.8 & - \\
\hline Inoue et al. $1996{\text { (Japan })^{3)}}^{3}$ & $13-69$ & 36 & 4.4 & $4.2^{*}$ & 4.5 & 4.8 & 5.6 \\
\hline This study (Nigeria) & $20-50$ & 102 & 4.9 & $4.5^{*}$ & 4.6 & 4.9 & 5.6 \\
\hline
\end{tabular}

Measurements are in millimeters ( $\mathrm{mm}$ )

SAC, space available for the spinal cord.

*Narrowest level.

ted outcome of spinal cord injured patients. The findings of low SAC may also indicate an increased predisposition of the study population to congenital cervical spinal canal stenosis and the subsequent possible risk of posttraumatic and degenerative myelopathy especially around the C4/5 level. Although other factors like mechanism of injury and duration of pressure on the spinal cord are known to affect outcomes in myeloradiculopathy, individuals with small SAC or sagittal canal dimension as observed in this study population have been shown in previous studies to be at an increased risk of myelopathy as well as recurrence of neurapraxia, ${ }^{8,9,11,13,15)}$.

Age has significant effect on SAC and contributes as high as $11.8 \%$ effect to the variations in the values of SAC. This indicates that the linear composite of SAC differs at different age groups. This effect is most marked at C3/4 level with $31.6 \%$ impact. We also observed that among the subaxial cervical spine segments measured, the transition levels (C3/4 and C7/T1) had the highest variation in SAC values. This implies that cervical spine trauma is likely to accelerate degenerative disease at these transition levels.

Although many studies using symptomatic adults show a statistically significant difference between genders ${ }^{5,6,12)}$, subgroup analysis in this study of asymptomatic adults found that the SAC did not show overall significant sex variation and gender contributed just $7 \%$ to variations in the value of SAC. Even at the different intervertebral disc levels measured, only the C6/7 and $\mathrm{C} 7 / \mathrm{T} 1$ levels had any significant variation in the average value of SAC between males and females although females generally had slightly higher SAC at other levels. The finding in this study may be a reflection of the social demographics of the samples since the study was centered in the city. In urban areas like Enugu, sex roles are gradually becoming less defined. In addition increasingly more women are participating in contact sports activities. Therefore, with these changing patterns of social behavior, the likelihood of differential exposure of a particular gender to the risk factors that accelerate degenerative changes is likely to be low. The result may be different if the study were carried out in the rural areas where for example the men, who are mainly farmers and artisans, are expected to carry heavy loads compared with the females who also have their defined sex roles such as housekeeping, cooking, and petty trading.

Another possible reason for the absence of sex difference is the methodology of this study. This study took measurements at the intervertebral disc level unlike most of the other studies that highlighted sex differences which took measurements at the midvertebral body level. We however believe that measurement taken at the disc level may be more sensitive and predictive of the risk of myeloradiculopathy. This finding is not isolated. Wong et al. ${ }^{16)}$ observed no gender difference in Pavlov ratio and midsagittal canal dimensions although the study was carried out among patients that already presented with significant clinical symptoms and without age restriction. Lee et al..$^{5}$ and Hukuda and Kojima ${ }^{2)}$ in separate studies also found a similar trend of no gender difference in midsagittal canal dimensions respectively.

Despite some limitations, this study has helped to establish reference values for SAC as a more direct cervical canal stenosis indicator for this study population. These values will form useful baseline for further studies and research in this field for this environment. It will also provide a base for clinical screening, early identification of individuals with pre-existing threat to the cervical spinal cord and follow-up of patients for early surgical decision making. Early identification and advice would help to reduce the risk of exposure from participation in certain high risk occupational, social and contact sports activities for individuals with increased predisposition to cervical spinal cord injury from pre-existing congenital or acquired canal stenosis especially at a relatively young age. Furthermore, the small value of SAC from this study population relative to results among Caucasians and other parts of the world implies that the risk of spinal cord injury is higher in this environment. Therefore every effort should be made to improve primary prevention strategies in order to minimize the already high morbidity and mortality associated with spinal cord injury. This requires access to health education, improved awareness of the risks of cervical spine injury, early detection of individuals at risk using reliable screening methods and frequent medical follow-up whenever indicated. Increased awareness of a pre-existing cervical canal stenosis may contribute immensely to reduction in the rate of permanent spinal cord injury for identified high risk patients.

In the study environment with a poor health seeking behaviour, significant proportion of patients still present to the expert quite late. Considering the higher possibility of onset of neurological deficit as a result of the reduced SAC in this study popula- 
tion compared to the Caucasians, a management model based on screening for early identification of patients at risk and subsequent clinical follow-up for future management decision may possibly be a better model than the current approach that relies solely on review of symptomatic patients. This would ensure that patients are operated on as soon as they become symptomatic before irreversible spinal cord injury occurs.

The findings from this study has strengthened the need for a local baseline of canal stenosis indicators instead of relying on data from other countries for screening, diagnosis or patient counseling since the clinical predictive value of data from other races would be poor in this study population. Further longitudinal clinical studies are needed to better clarify the usefulness of these measurements for screening, diagnosis and early surgical decision in patients at risk for myeloradiculopathy.

\section{CONCLUSION}

C4/5 and C5/6 are the narrowest subaxial cervical spine levels among asymptomatic adults with mean SAC of $4.4 \pm 1.2 \mathrm{~mm}$ and $4.6 \pm 1.2 \mathrm{~mm}$, respectively and probably explain the preponderance of C4/5 and C5/6 cord injury. This is different from European series but similar to Japanese series. However, there is no significant gender difference in the values of SAC of asymptomatic adults. Further clinically correlated studies would help to refine the mean SAC MSCSAC measurements into a more reliable clinical tool for the screening, advice of young adults for the level of risk of developing posttraumatic and degenerative myeloradiculopathy, early diagnosis of chronic stingers and as a decision guide for timing of cervical spinal decompressive surgery.

\section{CONFLICT OF INTEREST}

No potential conflict of interest relevant to this article was reported.

\section{REFERENCES}

1. Herzog RJ, Wiens JJ, Dillingham MF, Sontag MJ: Normal cervical spine morphometry and cervical spinal stenosis in asymptomatic professional football players. Plain film radiography, multiplanar computed tomography, and magnetic resonance imaging. Spine (Phila Pa 1976) 16(6 Suppl):S178-186, 1991

2. Hukuda S, Kojima Y: Sex discrepancy in the canal/body ratio of the cervical spine implicating the prevalence of cervical myelopathy in men. Spine (Phila Pa 1976) 27:250-253, 2002

3. Inoue $\mathrm{H}$, Ohmori K, Takatsu T, Teramoto T, Ishida Y, Suzuki K: Morphological analysis of the cervical spinal canal, dural tube and spinal cord in normal individuals using CT myelography. Neuroradiology 38:148-151, 1996

4. Ishikawa M, Matsumoto M, Fujimura Y, Chiba K, Toyama Y: Changes of cervical spinal cord and cervical spinal canal with age in asymptomatic subjects. Spinal Cord 41:159-163, 2003

5. Lee HM, Kim NH, Kim HJ, Chung IH: Mid-sagittal canal diameter and vertebral body/canal ratio of the cervical spine in Koreans. Yonsei Med J 35:446-452, 1994

6. Lim JK, Wong HK: Variation of the cervical spinal Torg ratio with gender and ethnicity. Spine J 4:396-401, 2004

7. Matveeva N, Lazarova D, Nakeva N, Zivadinovik J, Zafirova B: Cervical spinal canal measurements: indicators of spinal stenosis. Acta Morphol 9:20-23, 2012.

8. Prasad SS, O’Malley M, Caplan M, Shackleford IM, Pydisetty RK: MRI measurements of the cervical spine and their correlation to Pavlov's ratio. Spine (Phila Pa 1976) 28:1263-1268, 2003

9. Presciutti SM, DeLuca P, Marchetto P, Wilsey JT, Shaffrey C, Vaccaro AR: Mean subaxial space available for the cord index as a novel method of measuring cervical spine geometry to predict the chronic stinger syndrome in American football players. J Neurosurg Spine 11:264-271, 2009

10. Siemionow K, An H, Masuda K, Andersson G, Cs-Szabo G: The effects of age, sex, ethnicity, and spinal level on the rate of intervertebral disc degeneration: a review of 1712 intervertebral discs. Spine (Phila Pa 1976) 36:1333-1339, 2011

11. Taitz C: Anatomical observations of the developmental and spondylotic cervical spinal canal in South African blacks and whites. Clin Anat 9:395-400, 1996

12. Tatarek NE: Variation in the human cervical neural canal. Spine J 5:623-631, 2005

13. Teresi LM, Lufkin RB, Reicher MA, Moffit BJ, Vinuela FV, Wilson GM, et al: Asymptomatic degenerative disk disease and spondylosis of the cervical spine: MR imaging. Radiology 164:83-88, 1987

14. Tierney RT, Maldjian C, Mattacola CG, Straub SJ, Sitler MR: Cervical spine stenosis measures in normal subjects. J Athl Train 37:190-193, 2002

15. Torg JS, Corcoran TA, Thibault LE, Pavlov H, Sennett BJ, Naranja RJ Jr, et al: Cervical cord neurapraxia: classification, pathomechanics, morbidity, and management guidelines. J Neurosurg 87:843850, 1997

16. Wong TM, Leung HB, Wong WC: Correlation between magnetic resonance imaging and radiographic measurement of cervical spine in cervical myelopathic patients. J Orthop Surg (Hong Kong) 12: 239-242, 2004 